\title{
A QUANTITATIVE STUDY ON EXAMINING PERCEIVED SERVICE QUALITY IN LOCAL AIRLINES
}

\author{
DOI: 10.17261/Pressacademia.2018.889 \\ PAP- V.7-2018(42)-p.241-245
}

Sedat Belbag ${ }^{1}$, Aybegum Gungordu Belbag ${ }^{2}$

${ }^{1}$ Gazi University, School of Economics and Administrative Sciences, Ankara, Turkey. sedatbelbag@gazi.edu.tr, ORCID: 0000-0002-4136-2468

${ }^{2}$ Bartin University, School of Economics and Administrative Sciences, Bartin, Turkey. aybegum.gungordu@gmail.com, ORCID: 0000-0001-8704-0045

\section{To cite this document}

Belbag, S., Gungordu Belbag, A. (2018). A quantitative study on examining perceived service quality in local airlines. PressAcademia Procedia (PAP), V.7, p.241-245.

Permemant link to this document: http://doi.org/10.17261/Pressacademia.2018.889

Copyright: Published by PressAcademia and limited licenced re-use rights only.

\section{ABSTRACT}

Purpose- The purpose of this study is to measure perceived service quality in local airlines in Turkey with the help of a survey that benefits from SERVQUAL by using a multicriteria decision making method.

Methodology- Therefore, we evaluate three local airlines in Turkey in the context of perceived service quality and try to determine the best airline among them. We measure the perceived service quality in airlines with an interval type-2 fuzzy multi-criteria decision making method that aims to make unclear statements, which derives from decision makers, more meaningful. We apply a SERVQUAL based survey on consumers who experienced an airline service quality.

Findings- Considering the data obtained from surveys, we determine perception scores of decision makers through the factors that affects airlines service quality by using an interval type-2 fuzzy multi-criteria decision method.

Conclusion- Consequently, we determine the airline with the best service quality among three local airlines.

Keywords: Perceived service quality, airline transportation, fuzzy interval type 2 multi-criteria decision making method, SERVQUAL, multicriteria decision making methods.

JEL Codes: M10, M30, M31.

\section{YEREL HAVAYOLLARINDA ALGILANAN HIZMET KALITESININ INCELENMESI ÜZERINE KANTITATIF BIR} ARAŞTIRMA

\section{ÖZET}

Amaç- Mevcut çalışmanın amacı, Türkiye'deki yerel havayollarında algılanan hizmet kalitesini SERVQUAL'den faydalanan bir anket yardımıyla çok kriterli karar verme yöntemi kullanarak ölçmektir.

Yöntem- Bu sebeple, yurtiçinde faaliyet gösteren üç havayolu şirketi literatürde yer alan hizmet kalitesi kriterleri göz önünde bulundurularak değerlendirilmiş ve arasından en iyisi tespit edilmeye çalışılmıştır. Havayollarında algılanan hizmet kalitesi, karar vericilerden kaynaklanan belirsiz ifadeleri daha anlamlı hale getirmeyi amaçlayan bir Tip-2 bulanık çok kriterli karar verme modeli ile ölçülmüştür. Literatürdeki çeşitli çalışmalardan faydalanarak oluşturulan SERVQUAL temelli anket daha önceden havayolu hizmet kalitesini deneyimlemiş bireylere uygulanmıştır.

Bulgular- Anket neticesinde elden edilen verilere göre karar vericilerin havayolu hizmet kalitesini etkileyen kriterlere yönelik algı skorları tespit edilmiştir. Algı skorları göz önünde bulundurularak Tip-2 bulanık çok kriterli karar verme modeli ile hizmet kalitesi en iyi havayolu firması tespit edilmiştir.

Sonuç- Neticede, yerel havayollarında yer alan üç firmadan algılanan hizmet kalitesi en yüksek olan belirlenmiştir.

Anahtar Kelimeler: Algılanan hizmet kalitesi, havayolu taşımacılığı, Tip 2 Bulanık çok kriterli karar verme yöntemi, SERVQUAL, çok kriterli karar verme yöntemleri.

JEL Kodları: M10, M30, M31. 


\section{GiRiş}

Türkiye'nin hizmet ihracatında \%47,7 ile yolcu taşımacılı̆̆ hizmetleri 6 firma (Türk Hava Yolları, Pegasus, SunExpress, Atlasjet, Onur Air, Corendon) ile birinci sırada yer almaktadır. Türkiye'nin hizmet ihracatı sıralamasında hayayolları şirketleri önemli konumlarda yer almaktadır. Örneğin birinci Türk Hava Yolları (THY), üçüncü Pegasus, beşinci SunExpress hayayoludur. Dünyada havayolu taşımaclık hizmetleri bakımından ise Türkiye, ABD ve Birleşik Arap Emirlikleri'ni takip etmekte ve 2012-2016 yılları arasında bu iki ülkeyi takip etmektedir (Türkiye İhracatçılar Meclisi, 2017). 2016 yılında, Türkiye'den, iç hat ve dış hatlarda toplam 173.738 .174 kişi uçmuştur. İ̧̧ hatların bu uçuşlardaki payı \%59'dur. İç hat yolcu trafiğinde en büyük payı \%54 ile THY (AnadoluJet ile birlikte) alırken, lideri \%30 ile Pegasus takip etmektedir. Dış hat yolcu trafiğinde ise THY \%66'lık payıyla liderken, Pegasus \%15'lik payıyla onu izlemektedir (Havayolu Sektör Raporu, 2016).

Hizmetlerin algılanan kalitesinin analizinde pazarlama literatüründe SERVQUAL sıklıkla kullanılmaktadır. SERVQUAL, algılanan kaliteyi yani tüketicinin bir kurumun genel üstünlüğü hakkındaki yargısını ölçer. Algılanan hizmet kalitesinin SERVQUAL ile ölçümü, performansa yönelik algılarla beklentilerin kıyaslanmasından meydana gelir (Parasuraman vd., 1988). Parasuraman vd. (1988), SERVQUAL'in son halinde, müşterilerin herhangi bir kuruma ait algılanan hizmet kalitesini ölçen 22 maddeyi, beş boyutla belirtir: Somut varlıklar, güvenilirlik, cevap verebilirlik, garanti ve empati. SERVQUAL, çalışılan sektöre göre maddelerinin uyarlandığı ve/veya yeni maddelerin eklendiği bir ölçektir. Örneğin, Chou vd. (2011), havayolu hizmetleri için için hizmet kalitesi boyutları, somut varlıklar, cevap verebilirlik, güvenilirlik ve garanti, empati, uçuş güzergahları olarak belirtir.

SERVQUAL analizinde, algılanan ve beklenen hizmet kalitesi ortalamalarının farklarına (boşluklara) bakarak SERVQUAL skorlarına dayalı sıralamalar yapılmaktadır. Havayollarının hizmet kalitesini SERVQUAL analizinden faydalanarak ölçen çalışmalar (Fick ve Ritchie, 1991; Kozak vd., 2003; Shanka, 2012; Aydın ve Yıldıım, 2012a; Aydın ve Yıldııı, 2012b; Chikwendu vd., 2012) yaygındır. Literatürdeki sınırı sayıdaki çalışmalar ise havayollarının algılanan hizmet kalitesini ölçmede çok kriterli karar verme (ÇKKV) yöntemlerini uygulamıştır (bknz. Tablo 1). Mevcut çalışmanın amacı, Türkiye'deki yerel havayollarında algılanan hizmet kalitesini SERVQUAL'den faydalanan bir anket yardımıyla çok kriterli karar verme yöntemi kullanarak ölçmektir.

Tablo 1: Havayollarında Algılanan Hizmet Kalitesini Çok Kriterli Karar Verme Yöntemleriyle Ölçen Çalışmalar

\begin{tabular}{|l|l|}
\hline Yazarlar & Çok Kriterli Karar Verme Yöntemi \\
\hline Chang ve Yeh (2002) & Çok Kriterli Bulanık Model \\
\hline Tsaur vd. (2002) & AHP - TOPSIS \\
\hline Janic (2003) & TOPSIS \\
\hline Lee ve Chou (2006) & Çok Kriterli Bulanık Model \\
\hline Önüt vd. (2008) & AHP \\
\hline Nejati vd. (2009) & Bulanık TOPSIS \\
\hline Liou vd. (2011) & Modifiye Edilmiş VIKOR \\
\hline Kuo (2011) & Aralık Değerli Bulanık ÇKKV Yöntemi \\
\hline Torlak vd. (2011) & Bulanık TOPSIS \\
\hline Wu vd. (2013) & Bulanık AHP \\
\hline Liao (2013) & AHP- Bulanık TOPSIS \\
\hline Delice (2016) & Bulanık TOPSIS - Bulanık VIKOR \\
\hline
\end{tabular}

\section{VERI VE YÖNTEM}

Çalışmada, havayolu taşımacılığında algılanan hizmet kalitesini ölçmek üzere Parasuraman vd. (1998), Gilbert ve Wong (2003), Jiang (2013), Kurtulmuşoğlu vd. (2016)'nin çalışmalarından faydalanılarak bir anket oluşturulmuştur. Mevcut çalışmada, havayollarında algılanan hizmet kalitesi, Chen ve Lee (2010)'nin ortaya koymuş oldukları yeni bir yöntem olan Tip 2 Bulanık çok kriterli karar verme modeli ile ölçülmüştür. 25-35 yaş arasında, yükseköğrenim görmüş, yılda en az bir kez uçan 250 yolcu, kartopu örnekleme yöntemiyle çalışmanın örneklemini oluşturmuştur.

Bulanık çok kriterli karar verme modelinin tercih edilmesi, şu şekilde açıklanabilir. İnsanların yargıları ve tercihleri sıkıkla net bir sayıyla ifade edilemeyecek derecede belirsizdir (Chou vd., 2011). Karar vericiler karşılarına çıkan alternatifleri çeşitli kriterler göz önünde bulundurarak değerlendirme sürecinde dilsel değişkenlerden faydalanmaktadır. Dilsel değişken, karar vericilerin alternatifleri değerlendirirken kullandıkları kelime ya da kelime gruplarından oluşur. Örnek olarak, sıcaklık kavramı az, orta ya da çok gibi kelimelerle ifade edilmesi verilebilir. Bundan dolayı, dilsel değişkenler kişilerin geçmişteki farkı tecrübelerinden dolayı belirsizlik içerebilmektedir. Zadeh (1975), dilsel değişkenlerden kaynaklanan belirsizliğin üstesinden gelebilmek amacıyla bulanık sayı ve bulanık küme kavramlarını önermiştir. Bulanık küme içerisinde yer alan dilsel değişkenler sadece 0 veya 1 değerinde tanımlanmayıp, 0 ve 1 arasında değerler olarak da tanımlanabilmektedir. Bulanık mantık belirsiz ve kesin olmayan bilgileri kullanarak basit ve kolay bir şekilde sonuçlara ulaşılmasını sağlar (Agarwal ve Jain, 2013).

Tip 2 bulanık mantık sistemi, tip 1 bulanık mantık sisteminin geliştirilmesi ile ortaya çıkmıştır. Tip 1 mantık sisteminde girdilerin üyelik dereceleri kesin ya da belirlenebilir (crisp) yapıdayken, tip 2 bulanık mantık sisteminde girdilerin üyelik dereceleri bulanık ya da belirsiz (fuzzy) yapıdadır. Genel bir tip 2 bulanık mantık sistemi Şekil 1'de gösterilmektedir. Tip 2 bulanık mantık sisteminde yer alan girdilerdeki belirsizlik tamamen ortadan kaldırıldığında sistem tip 1 bulanık yapıya dönüşür. 


\section{Şekil 1: Tip 2 Bulanık Mantık Sistemi}

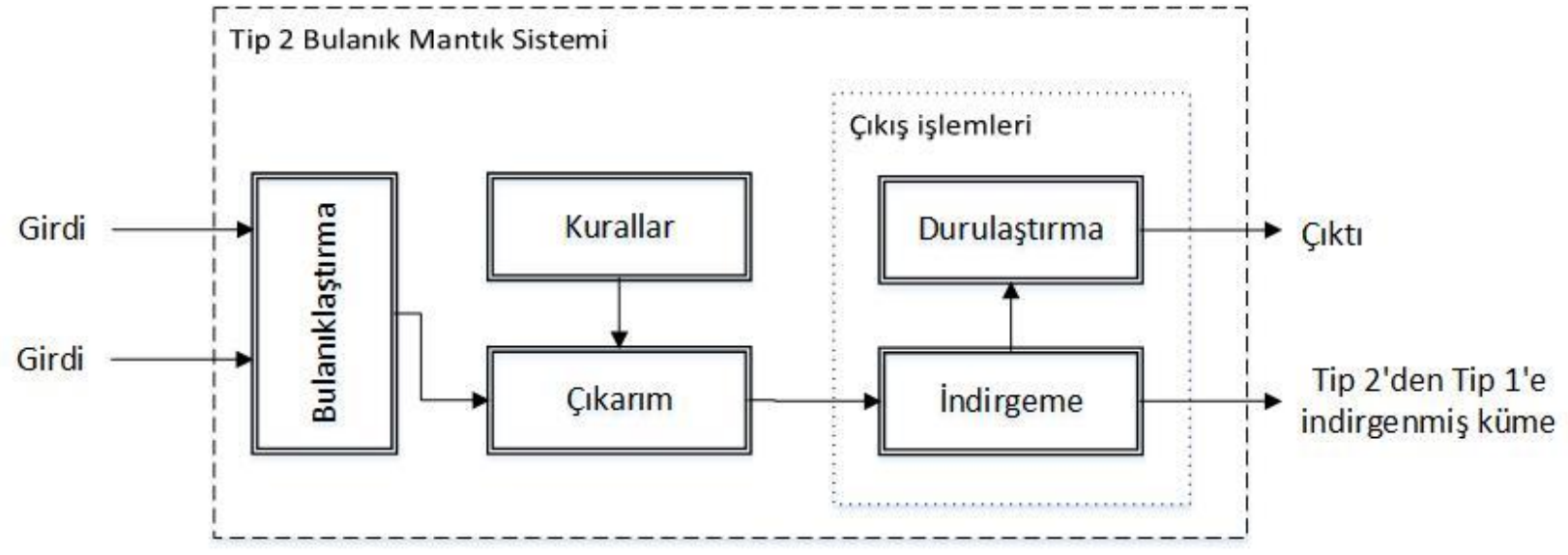

Bulanık sayıların üyelik dereceleri 0 ve 1 arasındaki sayılar yardımıyla ifade edilmektedir. Tip 2 bulanık mantık sisteminde yer alan sayılar kümesi ise üst $\left(A_{i}^{U}\right)$ ve alt $\left(A_{i}^{L}\right)$ üyelik fonksiyonları ile tanımlanmaktadır. Bir Tip 2 bulanık mantık sisteminde yer alan küme Denklem $1^{\prime}$ deki şekilde ifade edilmektedir.

$$
\breve{A}_{i}=\left(A_{i}^{U}, A_{i}^{L}\right)=\left(\left(a_{i 1}^{U}, a_{i 2}^{U}, a_{i 3}^{U}, a_{i 4}^{U}, H_{1}\left(A_{i}^{U}\right), H_{2}\left(A_{i}^{U}\right)\right),\left(a_{i 1}^{L}, a_{i 2}^{L}, a_{i 3}^{L}, a_{i 4}^{L}, H_{1}\left(A_{i}^{L}\right), H_{2}\left(A_{i}^{L}\right)\right)\right)(1)
$$

Bu çalışmada, Tip 2 bulanık mantık temelli birçok kriterli karar verme yöntemi kullanılarak havayollarında algılanan hizmet kalitesi ölçülmüştür. Kullanılan yöntem birden fazla karar vericinin çeşitli alternatiflerin algılanan hizmet kalitesi hakkında beyan ettiği bilgilerdeki belirsizliği en aza indirerek en uygun alternatifin belirlenmesini amaçlamaktadır. $k$ sayıdaki karar vericinin $\left(D=\left\{d_{1}, d_{2}, d_{3}, \ldots, d_{k},\right\}\right) n$ sayıdaki alternatifi $\left(A=\left\{a_{1}, a_{2}, a_{3}, \ldots, a_{n},\right\}\right) m$ sayıdaki kriterleri $\left(C=\left\{c_{1}, c_{2}, c_{3}, \ldots, c_{m},\right\}\right)$ göz önünde bulundurarak değerlendirdiğini düşünelim. Bu varsayımlara göre yöntemin aşamaları şu şekilde devam etmektedir:

Aşama 1: Her bir karar vericiye göre karar matrisi oluşturarak, ortalama karar matrisini düzenlemek.

$$
\begin{gathered}
f_{i j}^{p}=\left[\begin{array}{ccc}
f_{11} & \cdots & f_{1 n} \\
\vdots & \ddots & \vdots \\
f_{m 1} & \cdots & x_{m n}
\end{array}\right] \text { (2) } \\
\bar{F}=\tilde{f}_{i j}, \quad \tilde{f}_{i j}=\left(\frac{f_{i j}^{1}+f_{i j}^{2}+\cdots+f_{i j}^{k}}{k}\right)
\end{gathered}
$$

Aşama 2: Her bir karar vericiye göre ağırlık matrisi oluşturarak, ortalama ağırlık matrisini düzenlemek.

$$
\begin{gathered}
w_{i}^{p}=\left[w_{i}^{1}, w_{i}^{2}, \ldots, w_{m}^{p}\right](4) \\
\bar{W}=\widetilde{w}_{i j}, \quad \widetilde{w}_{i j}=\left(\frac{w_{i j}^{1}+w_{i j}^{2}+\cdots+w_{i j}^{k}}{k}\right)
\end{gathered}
$$

Aşama 3: Ağırlıklandırılmış karar matrisini oluşturmak. Burada alternatiflerin değerlendirilmesinde fayda sağlayan kriterler toplanırken, maliyet oluşturan kriterler ise çıkarılmaktadır. Denklemde $F_{1}$ fayda sağlayan kriter kümesi iken, $F_{2}$ maliyet oluşturan kriter kümesini temsil etmektedir.

$$
\tilde{d}_{j}=\left(\sum_{i=1, f_{i} \in F_{1}}^{m}\left(\widetilde{w}_{i} x \tilde{f}_{i j}\right)-\sum_{i=1, f_{i} \in F_{2}}^{m}\left(\widetilde{w}_{i} x \tilde{f}_{i j}\right)\right)
$$

Aşama 4: Her bir alternatif için sıralama değeri hesaplanarak en büyük sıralama değerine sahip alternatifi tespit etmek. Sıralama için gereken işlemler aşağıdaki denklemler yoluyla gerçekleşir.

$p\left(\tilde{A}_{i}^{U} \geq \tilde{A}_{k}^{U}\right)=\max \left(1-\max \left(\frac{\sum_{g=1}^{4} \max \left(a_{k g}^{U}-a_{i g}^{U}, 0\right)+\left(a_{k 4}^{U}-a_{i 1}^{U}\right)+\sum_{g=1}^{2} \max \left(H_{g}\left(\tilde{A}_{k}^{U}\right)-H_{g}\left(\tilde{A}_{i}^{U}\right), 0\right)}{\sum_{g=1}^{4} \max \left|a_{k g}^{U}-a_{i g}^{U}\right|+\left(a_{k 4}^{U}-a_{i 1}^{U}\right)+\sum_{g=1}^{2} \max \left|H_{g}\left(\tilde{A}_{k}^{U}\right)-H_{g}\left(\tilde{A}_{i}^{U}\right)\right|}, 0\right), 0\right)$ (7)
$p\left(\tilde{A}_{i}^{L} \geq \tilde{A}_{k}^{L}\right)=\max \left(1-\max \left(\frac{\sum_{g=1}^{4} \max \left(a_{k g}^{L}-a_{i g}^{L}, 0\right)+\left(a_{k 4}^{L}-a_{i 1}^{L}\right)+\sum_{g=1}^{2} \max \left(H_{g}\left(\tilde{A}_{k}^{L}\right)-H_{g}\left(\tilde{A}_{i}^{L}\right), 0\right)}{\sum_{g=1}^{4} \max \left|a_{k g}^{L}-a_{i g}^{L}\right|+\left(a_{k 4}^{L}-a_{i 1}^{L}\right)+\sum_{g=1}^{2} \max \left|H_{g}\left(\tilde{A}_{k}^{L}\right)-H_{g}\left(\tilde{A}_{i}^{L}\right)\right|}, 0\right), 0\right)$ 


$$
\begin{gathered}
\operatorname{Rank}\left(\tilde{A}_{i}^{U}\right)=\frac{1}{n(n-1)}\left(\sum_{k=1}^{n} p\left(\tilde{A}_{i}^{U} \geq \tilde{A}_{k}^{U}\right)+\frac{n}{2}-1\right) \\
\operatorname{Rank}\left(\tilde{A}_{i}^{L}\right)=\frac{1}{n(n-1)}\left(\sum_{k=1}^{n} p\left(\tilde{A}_{i}^{L} \geq \tilde{A}_{k}^{L}\right)+\frac{n}{2}-1\right)(10) \\
\operatorname{Rank}\left(\tilde{A}_{i}\right)=\frac{\operatorname{Rank}\left(\tilde{A}_{i}^{U}\right)+\operatorname{Rank}\left(\tilde{A}_{i}^{L}\right)}{2}(11)
\end{gathered}
$$

\section{BULGULAR VE TARTIŞMA}

Bu bölümde Türkiye'de faaliyet gösteren Türk Hava Yolları (THY), AndoluJet ve Pegasus Havayolları'nın önerilen çok kriterli karar verme yöntemi kullanılarak algılanan hizmet kaliteleri değerlendirilmektedir. Karar vericiler dikkate alınan havayolu şirketlerini deneyimleyen kişiler arasından seçilmiştir. Belirlenen işletmelerin algılanan hizmet kalitesi toplamda 41 kriter göz önünde bulundurularak değerlendirilmiştir. Kriterler bazıları SERVQUAL analizinde de yer alan yedi grup altında toplanmıştır (güvenilirlik, garanti, olanaklar, çalışanlar, uçuş güzergâhları, kişiselleştirme, cevap verebilirlik). Alternatiflerin değerlendirilmesinde bir önceki bölümde açıklanan çok kriterli karar verme yönteminin aşamaları izlenmektedir.

Tablo 2, bir önceki bölümde bahsedilen çok kriterli karar verme yöntemi ile elde edilen sonuçları göstermekle birlikte alternatifler arasındaki nihai sıralamayı göstermektedir. Bu sonuca göre karar vericiler tarafından AnadoluJet tüm alternatifler arasında en yüksek algılanan hizmet kalitesine sahip havayolu olduğu ortaya çıkmıştır. İkinci sırayı çok az bir farkla THY alırken, son sırada Pegasus Havayolları yer almıştır. AnadoluJet havayollarının hizmet kalitesi en yüksek havayolu şirketi olarak görülmesinin sebeplerinden biri daha düşük fiyata daha yüksek kalitede hizmet sunmasıdır. Her ne kadar yurtiçi uçuşlara odaklansa da bir THY iştiraki olarak üst düzey hizmet kalitesinden ödün vermemesi karar vericiler açısından önem arz etmektedir.

\section{Tablo 2: Alternatifler Arasındaki Nihai Sıralama}

\begin{tabular}{l|cc}
\hline \hline \multirow{2}{*}{ Rank } & $A_{1}$ & 0,357 \\
& $A$ & 0,367 \\
& $A$ & 0,274 \\
\hline \hline
\end{tabular}

\section{SONUÇ}

Bu çalışma Türkiye'de yerel havacılıkta piyasanın ilk üç havayolu firması algılanan hizmet kalitesi açısından değerlendirilmiştir. Hizmet kalitesini ölçmek amacıyla SERVQUAL temelli bir anket oluşturulmuştur. Dikkate alınan firmalarda daha önce yolculuk yapmış kişilerden bu firmaları çeşitli kriterler doğrultusunda değerlendirmeleri istenmiştir. Karar vericilerden elde edilen veriler bir bulanık çok kriterli karar verme yöntemi yardımı ile analiz edilmiştir.

Sonuçlara göre Türkiye'de yerel havacılık sektöründe faaliyet gösteren ilk üç firma arasından algılanan hizmet kalitesi en yüksek olan firma AnadoluJet olarak belirlenmiştir. İkinci sırayı THY ve üçüncü sırayı da Pegasus Havayolları almıştır. AnadoluJet ile THY firmalarının skorlarının oldukça yakın olmasının bir sebebi aynı şirketler grubuna dâhil olması olarak gösterilebilir. AnadoluJet'in yerel havacılık üzerine maliyet odaklı bir firma olmasına karşın THY yurtdışı uçuşlara odaklanması aradaki küçük farkı açıklayabilir.

\section{KAYNAKLAR}

Agarwal, S., Jain, C. (2013). Customer oriented product selection using fuzzy approach. International Journal of Emerging Trends in Engineering and development, 3(2), 234-247.

Aydin, K., Yildirim, S. (2012a). The measurement of service quality with servqual for different domestic airline firms in Turkey. Serbian Journal of Management, 7(2), 219-230.

Aydın, K., Yıldırım, S. (2012b). Service quality in airline businesses: a research on THY, Kocaeli Üniversitesi Sosyal Bilimler Enstitüsü Dergisi, 24, 35-49.

Chang, Y. H., Yeh, C. H. (2002). A survey analysis of service quality for domestic airlines. European journal of operational research, 139(1), 166-177.

Chen, S. M., Lee, L. W. (2010). Fuzzy multiple attributes group decision-making based on the ranking values and the arithmetic operations of interval type-2 fuzzy sets. Expert Systems with applications, 37(1), 824-833.

Chou, C. C., Liu, L. J., Huang, S. F., Yih, J. M., Han, T. C. (2011). An evaluation of airline service quality using the fuzzy weighted SERVQUAL method. Applied Soft Computing, 11(2), 2117-2128.

Chikwendu, D. U., Ejem, E., Ezenwa, A. (2012). Evaluation of service quality of Nigerian airline using servqual model. Journal of Hospitality Management and tourism, 3(6), 117-125. 
Delice, E. K. (2016). Havayolu firmalari seçimi için bulanik çok kriterli bir model. Gazi Üniversitesi Mühendislik-Mimarlık Fakültesi Dergisi, 31(2).

Fick, G. R., Brent Ritchie, J. R. (1991). Measuring service quality in the travel and tourism industry. Journal of Travel Research, 30(2), 2-9.

Gilbert, D., Wong, R. K. (2003). Passenger expectations and airline services: a Hong Kong based study. Tourism Management, 24(5), 519532.

Havayolu Sektörü Raporu (2016). dhmi.gov.tr/getBinaryFile.aspx?Type=14\&dosyalD=2192

Janic, M. (2003). Multicriteria evaluation of high-speed rail, transrapid maglev and air passenger transport in Europe. Transportation Planning and Technology, 26(6), 491-512.

Jiang, H. (2013). Service quality of low-cost long-haul airlines - the case of Jetstar Airways and AirAsia X. Journal of Air Transport Management, 26, 20-24.

Kozak, N., Karatepe, O. M., Avcl, T. (2003). Measuring the quality of airline services: evidence from Northern Cyprus. Tourism Analysis, 8(1), 75-87.

Kuo, M. S. (2011). A novel interval-valued fuzzy MCDM method for improving airlines' service quality in Chinese cross-strait airlines. Transportation Research Part E: Logistics and Transportation Review, 47(6), 1177-1193.

Kurtulmuşoğlu, F. B., Can, G. F., Tolon, M. (2016). A voice in the skies: listening to airline passenger preferences. Journal of Air Transport Management, 57, 130-137.

Lee, H. S., Chou, M. T. (2006, October). A fuzzy multiple criteria decision making model for airline competitiveness evaluation. In International Conference on Knowledge-Based and Intelligent Information and Engineering Systems (pp. 902-909). Springer, Berlin, Heidelberg.

Liao, C. N. (2013). A fuzzy approach to business travel airline selection using an integrated AHP-TOPSIS-MSGP methodology. International Journal of Information Technology \& Decision Making, 12(01), 119-137.

Liou, J. J., Tsai, C. Y., Lin, R. H., Tzeng, G. H. (2011). A modified VIKOR multiple-criteria decision method for improving domestic airlines service quality. Journal of Air Transport Management, 17(2), p. 57-61.

Nejati, M., Nejati, M., Shafaei, A. (2009). Ranking airlines' service quality factors using a fuzzy approach: study of the Iranian society. International Journal of Quality \& Reliability Management, 26(3), 247-260.

Önüt, S., Akbaş, S., Yılmaz, G. (2008). The comparison of service quality of domestic airlines in Turkey. Sigma, 25(4), 349-358.

Parasuraman, A., Zeithaml, V. A., Berry, L. L. (1988). Servqual: a multiple-item scale for measuring consumer perc. Journal of retailing, 64(1), 12.

Shanka, M. S. (2012). Measuring service quality in Ethiopian airlines. Journal of Educational and Social Research, 2(9), 173-180.

Torlak, G., Sevkli, M., Sanal, M., Zaim, S. (2011). Analyzing business competition by using fuzzy TOPSIS method: an example of Turkish domestic airline industry. Expert Systems with Applications, 38(4), 3396-3406.

Tsaur, S. H., Chang, T. Y., Yen, C. H. (2002). The evaluation of airline service quality by fuzzy MCDM. Tourism management, 23(2), 107-115.

Türkiye İhracatçlar Meclisi (2017). Türkiye'nin 500 Büyük Hizmet Ihracatçısl,
http://www.tim.org.tr/files/downloads/Hizmet500/T\%C3\%BCrkiye'nin\%20500\%20B\%C3\%BCy\%C3\%BCk\%2OHizmet\%20\%C4\%BOhracat\%C3 \%A7\%C4\%B1s\%C4\%B1.pdf.

Wu, C., Zhang, X. Y., Yeh, I., Chen, F. Y., Bender, J., Wang, T. N. (2013). Evaluating competitiveness using fuzzy analytic hierarchy process -a case study of Chinese airlines. Journal of Advanced Transportation, 47(7), 619-634. 